\title{
Um Direito sem Estado: a noção de autonomia como fundamento da constituição jurídica medieval ${ }^{1}$
}

\section{PAOLO GROSSI}

\begin{abstract}
Professor emérito de História do Direito Medieval e Moderno na Università Degli Studi di Firenze (Itália). Doutor honoris causa pelas Universidades de Bologna (Itália), Napoli (Itália), Frankfurt am Main (Alemanha), Stockholm (Suécia), Autónoma de Barcelona (Espanha), Autónoma da Madrid (Espanha), Sevilla (Espanha), Universidade Federal do Rio Grande do Sul (Brasil) e Universidade Federal do Paraná (Brasil). Presidente emérito da Corte Constitucional da República Italiana.
\end{abstract}

\section{TRADUÇÃO: FELIPE PANTE LEME DE CAMPOS²}

SUMÁRIO: 1 A constituição jurídica medieval e as lentes do atual historiador do direito $\bullet 2 \mathrm{~A}$ profunda historicidade de Estado e soberania enquanto padrões que ordenam o universo jurídico moderno 3 Sociedade, direito, poder político: tipicidade do universo jurídico medieval • 4 A noção de autonomia enquanto adequado modelo ordenador para a compreensão da constituição jurídica medieval 5 Referências.

RESUMO: O presente artigo pretende propor a noção de autonomia como chave de compreensão da constituição jurídica medieval. A proposta parte da preocupação em evitar o anacronismo da projeção de conceitos tão marcadamente modernos, como Estado e soberania, na Idade Média, isto é, de noções que tendem a absolutizar e a ver o direito como expressão de um ente político totalizante. Já a noção de autonomia, despida de todo caráter estatalista e entendida como autonomia institucional, permite uma compreensão melhor de uma experiência jurídica pluralista como a medieval, em que o direito é muito mais a ossatura invisível da sociedade e não tanto um reflexo da vontade do poder político, que, por sua vez, imersos em um tecido de relações, pouco atuavam como legisladores ou como soberanos absolutos de determinado território (o que guarda paralelismo com o caráter não absoluto do dominium medieval, instituto de direito privado).

PALAVRAS-CHAVE: Constituição Jurídica Medieval • Estado • Soberania.

1 A versão original em italiano deste artigo foi publicada como "Un Diritto senza Stato (La nozione di autonomia come fondamento dela costituzione giuridica medievale)" no Quaderni fiorentini per la storia del pensiero giuridico moderno, n. 25, p. 267-284, 1996.

2 Doutorando em Teoria e Storia del Diritto pela Università Degli Studi di Firenze (Itália). Mestre em Direito pelo Programa de Pós-Graduação em Direito da Universidade Federal de Santa Catarina (UFSC). Bacharel em Direito pela Universidade de Fortaleza (UNIFOR). Membro do grupo de pesquisa CNPq-UFSC lus Commune em História da Cultura Jurídica.E-mail: felipe.pantelemedecampos@unifi.it. 


\section{A Law without a State: The notion of autonomy as the foundation of the medieval legal constitution}

CONTENTS: 1 The medieval legal constitution and the lenses of the current historian of Law • 2 The deep historicity of State and sovereignty as standards that lead the modern legal universe • 3 Society, law, political power: typicality of the medieval legal universe $\bullet 4$ The notion of autonomy as appropriate model for the understanding of the medieval legal constitution 5 References.

ABSTRACT: This paper intends to propose the notion of autonomy as a key to understanding the medieval legal constitution. The proposal starts from the concern to avoid the anachronism of the projection of concepts so markedly modern, as State and sovereignty, in the Middle Ages, that is, of notions that tend to absolutize and to see the Law as an expression of a totalizing political entity. The notion of autonomy, stripped of any statist character and understood as institutional autonomy, allows a better understanding of a pluralistic legal experience such as the medieval one, in which law is much more the invisible pillar of society and not so much a reflection of the will of the political power, which, in turn, immersed in a set of relations, acted little as legislators or absolute rulers of a particular territory (which has a correlation with the non-absolute character of the medieval dominium, institute of private law).

KEYWORDS: Medieval Legal Constitution • State • Sovereignty. 


\section{Un derecho sin Estado: La noción de autonomía como fundamento de la constitución jurídico medieval}

CONTENIDO: 1 La constitución jurídica medieval y las lentes del actual historiador del derecho • 2 La profunda historicidad de Estado y soberanía como patrones que ordenan el universo jurídico moderno - 3 Sociedad, derecho, poder político: tipicidad del universo jurídico medieval • 4 La noción de autonomía como adecuado modelo ordenador para la comprensión de la constitución jurídica medieval 5 Referencias.

RESUMEN: Este artículo pretende proponer la noción de autonomía como clave para la comprensión de la constitución jurídica medieval. La propuesta parte de la preocupación por evitar el anacronismo de la proyección de conceptos tan marcadamente modernos, como Estado y soberanía, en la Edad Media, es decir, de nociones que tienden a absolutizar y ver el derecho como expresión de un ente político totalizante. La noción de autonomía, desnuda de todo carácter estatalista y entendida como autonomía institucional, permite una comprensión mejor de una experiencia jurídica pluralista como la medieval, en que el derecho es mucho más la estructura invisible de la sociedad y no tanto un reflejo de la voluntad del poder político, que, a su vez, inmersos en un tejido de relaciones, poco actuaban como legisladores o como soberanos absolutos de determinado territorio (lo que guarda paralelismo con el carácter no absoluto del dominium medieval, instituto de derecho privado).

PALABRAS CLAVE: Constitución Jurídica Medieval • Estado • Soberanía. 


\section{A constituição jurídica medieval e as lentes do atual historiador do direito}

O historiador do direito que almeja realizar plenamente o seu ofício e não queira - traindo-o - limitar-se a, tal qual o contador, tão somente enumerar os dados oferecidos pelo passado, deve ter uma adequada compreensão em relação a esses dados. Isso exige uma harmônica combinação de duas atitudes aparentemente (tão somente) conflitantes: o respeito pela mensagem peculiar dos dados/informações analisados, mas também uma apropriação desses dados a fim de configurá-los enquanto patrimônio do próprio presente espiritual.

É inútil insistir, atualmente, em uma elementar verdade metodológica: o historiador, homem do hoje, não pode ler o passado senão com os seus olhos, vestindo as lentes que à sua vista lhe sejam convenientes; para além da metáfora, não pode deixar de utilizar os próprios cânones metodológicos e aquele conjunto de categorias ordenadoras que, interpretando, conceituando, sistematizando, permitem-lhe (e tão somente por meio deste caminho) constatar a peculiaridade da mensagem histórica. De fato, subtraído à miséria e à contingência dos fatos particulares, aquela mensagem pode lhe falar uma linguagem familiar; pode ser, então, claramente compreendida 3 .

Tudo isso é sacrossanto, mas sob uma condição: que o historiador não pretenda projetar indiscriminadamente as suas próprias categorias ordenadoras fazendo com que a realidade do passado seja comprimida dentro de armaduras que a sacrifiquem e que a sufoquem, pois essa condição impede uma efetiva e justa compreensão. 0 historiador tem o dever de usar essas categorias, mas deve fazê-lo em conformidade e em respeito à mensagem que provém do material histórico. A operação a ser cumprida é, portanto, analisar a relação entre conteúdos históricos e modelos teóricos. Somente assim é possível validamente ordená-los, aqueles primeiros.

Infelizmente, não ocorre sempre dessa forma: de modo frequente, de fato, encontramo-nos diante de reconstruções históricas do direito que são transformadas em perigosas deturpações simplesmente porque o reconstrutor não adotou a análise essencial, ora indicada, e porque pretendeu projetar no passado - sem qualquer crivo e sem qualquer cautela - as noções que lhe são mais familiares. A consequência mais marcante, os deslizes mais crassos, acontecem quando o historiador tem que lidar com experiências separadas do hoje por um profundo fosso de descontinuidade; por exemplo, com a experiência jurídica medieval, planeta jurídico caracterizado 
por fundações e peculiaridades originárias e originais, e, exatamente por isso, não passível de transplantes simplórios.

Diante da constituição jurídica medieval ${ }^{4}$, o atual historiador do direito tem por tarefa primeira - como escrevemos anteriormente em um trabalho de síntese completa ${ }^{5}$ - a submissão a um verdadeiro banho de purificação interior, sob pena de deturpação histórica e de um resultado interpretativo danoso, pois artificial e falseador.

Pretende-se aqui confirmar e, ao mesmo tempo, analisar com maior atenção, no plano teórico, tudo o que foi de modo amplo sustentado naquele trabalho anteriormente mencionado, ou seja, o quanto são inúteis noções e padrões ordenadores como Estado e soberania. E, ao contrário, a substancial utilidade da noção de autonomia para focar a constituição jurídica medieval. Se nos é permitido mesmo neste momento reiterá-lo, é tão somente porque é comum e praticamente unívoco o descuido no uso historiográfico de Estado e de soberania aplicados no medievo.

Estamos satisfeitos que este ensaio seja dedicado a honrar Roman Schnur ${ }^{6}$. Dentre os muitos méritos do notável historiador e juspublicista de Tübingen, deve-se destacar o mérito de ter promovido e organizado, em 1965, a tradução para o alemão das contribuições mais relevantes de Maurice Hauriou acerca da teoria da instituição ${ }^{7}$ e, em 1975, até mesmo do "L'ordinamento giuridico" de Santi Romano ${ }^{8}$, ou seja, dos mais significativos clássicos de uma doutrina jurídica inclinada a dividir, lógica e historicamente, o direito e o Estado; inclinada a subtrair o direito do abraço sufocante do Estado.

4 Constituição no sentido schmittiano e brunneriano Verfassung: esclarecimento talvez pleonástico, mas que pretende evitar equívocos.

5 Vide Grossi, 1995.

6 Em alemão e em uma escrita ainda mais reduzida, o ensaio foi publicado também na Festschrift für Roman Schnur, promovida pela Hochschule für Verwaltungswissenschaften de Speyer. Exatamente no momento em que se estregava esta contribuição ao nosso editor para a impressão, chega-me a notícia, cortesmente fornecida pelos familiares, que Roman Schnur, após prolongada doença, faleceu aos 5 de agosto deste ano de 1996. À sua memória, segue agora, em reverência, o meu pensamento.

7 Vide Hauriou, 1965. Ainda, organizado pelo próprio Schnur, veja-se a coleção: Institution und Recht, Darmstadt, Wiss, Buchgesells, 1968.

8 Vide Romano, S., 1975. Foi sobretudo após essa tradução que surgira, na Alemanha, um considerável florescer de obras inspiradas no pluralismo jurídico. A acurada percepção cultural de Schnur fê-lo aspirar a traduzir para o alemão também "ein anderes bedeutsames rechtstheoretisches Werk Santi Romanos, seins letztes Buch, nämlich 'Frammenti di un dizionario giuridico'. Que Schnur tivesse razão, demonstram as nossas anotações mais à frente. Não me parece, porém, ainda hoje, que essa aspiração verificara uma continuação. 


\section{A profunda historicidade de Estado e soberania enquanto padrões que ordenam o universo jurídico moderno}

Quando se afirma que o conceito Estado é inutilizável, não se refere somente ao seu invólucro terminológico, o qual, como todos sabemos, tem tido uma conturbada e descontínua história semântica; assumindo, por sua vez, apenas recentemente, o significado que hoje the vem atribuído (MIGLIO, 1981; 1988, p. 2).

Refere-se, em vez disso, a uma determinada presença político-jurídica, a um determinado sujeito político. Não se refere, então, a uma presença qualquer ou a um sujeito qualquer, como fazem aqueles que usam do termo e do conceito para individualizar qualquer ente que exerça uma supremacia política projetada em uma determinada porção territorial e que, assim fazendo-o, acabam por se lançar em um pântano de equívocos do qual é depois difícil retirar-se?

O problema, a bem da verdade, é que o Estado tem tido (e tem ainda) na nossa consciência um significado preciso. Tornou-se - por toda a idade moderna, e mesmo hoje - o modelo que ordena uma precisa realidade histórico-política, tornou-se uma categoria histórica de enorme valor interpretativo; porta consigo, então, uma enorme historicidade, a qual, assimilada à descontinuidade terminológica e à descontinuidade substancial de significado, acentuava de maneira pujante.

Quando, portanto, afirmamos que o conceito de Estado é inutilizável para ordenar a complexa realidade político-jurídica medieval, a menção imediata e exclusiva à qual se refere é - e outra não poderia ser - a noção tal qual fora delineada e sedimentada na nossa atual consciência. É a única que podemos projetar no passado e com a qual podemos verificar a realidade anterior, a única que pode se nos apresentar como correta para a comparação. A comparação se faz, desta forma, límpida, ou seja, evitam-se as brumas e as deturpações inerentes às perigosas abstrações genéricas. Desse modo, a dialética passado-presente se propõe com os necessários contornos bem definidos.

Estado é, portanto, na nossa opinião, um modelo ordenador específico e inequívoco nos seus respectivos conteúdos político-jurídicos. É uma realidade rigorosamente unitária, em que unidade significa, no plano material, efetividade de poder sobre um determinado território, garantida por um aparato centrípeto de organização e coação; e, no plano psicológico, uma vontade totalizante que tende a

90 exemplo mais evidente, e também o mais marcado de incompreensão metodológica, é aquele fornecido por MITTEIS, 1940 (com inúmeras edições posteriores). 
absorver e a tomar como sua toda e qualquer manifestação ao menos intersubjetiva que se realize no respectivo território. É um macrocosmo unitário que tende a se colocar enquanto estrutura global cuja vontade é, também, globalizante. Estado, portanto, implica um sujeito político forte, é a encarnação histórica de um poder político perfeitamente realizado, completo.

Se assim o é, o Estado é uma noção que possui um seu nicho histórico preciso, e do qual não pode ser retirado senão sob um risco inerente. De fato, o terreno temporal próprio a esse sujeito é, sem qualquer dúvida, o moderno, do qual é, então, o fruto quiçá mais vistoso e corpulento, e até mesmo o mais expressivo. Não se trata de reafirmar um lugar comum, mas uma verdade histórica. É só na modernidade que se verifica uma sempre crescente proliferação de sujeitos políticos que se propõem - para fins de efetividade do poder, mas, sobretudo para fins de psicologia do poder - como autênticos Estados, de Estados que são sempre mais Estados, até desembocarem naquela criatura do final do século 18, a qual, para o jurista, é o Estado criador e produtor do direito, justamente porque assaz interessado em toda e qualquer manifestação do jurídico. Estado legislador porque consciente da relevância política do jurídico e, consequentemente, controlador e monopolizador deste último ${ }^{10}$.

O Estado é um sujeito político corpulento, é um titereiro porque pretende manipular, sozinho, todos os fios do tecido social. A sua dimensão peculiar, a soberania, enquanto "puissance absôlüe et perpetuelle d'une République" (BODIN, 1977, p. 122) $)^{11}$ acentua-lhe a solidão e the caracteriza, por sua vez, como uma mônada que retira de si mesma a sua razão existencial, de sua própria

10 E Bodin, teórico da nova République, encharcado de modernidade, em sua acurada diagnose políticojurídica, teve uma percepção fundada: “le point principal de la maiesté souveraine et puissance absolüe gist principalemente à donner loy aux subiects en general sans leur consentemente" (J. Bodin, Les six livres de la République, Aalen Scientia, 1977 (rist. Anast.), p. 142. O testemunho de Bodin é, na nossa opinião, já plenamente caracterizável como moderno, mesmo se nele encontramos perfeitamente tracejos medievais, ainda presentes na França do final do séc. XVI. Acerca da complexidade da mensagem de Bodin insistese - ainda que excessivamente - já no incunábulo daquela que viria a ser a reflexão juspublicística do século XX, a exemplo do ensaio clássico de Heller de 1927: Hermann Heller, La sovranità-Contributo alla teoria del diritto dello Stato e del diritto Internazionale, também em H. H., La sovranità ed altri scritti sulla dottrina del diritto e dello Stato, a cura di P. Pasquino, Milano, Giuffrè, 1987, sobretudo p. 70 e ss. Eloquente, porém, é a precisa colocação de Bodin na estreia do moderno na primeira tentativa de revisão (e quase de refutação) do conceito tradicional, o ensaio de Kelsen de 1920, após o qual se pode afirmar, exatamente como a entendeu Merkl, que a história da ideia de soberania, ainda que de um ponto de vista terminológico, acaba por desdobrar-se drasticamente sob uma perspectiva semântica (veja-se Hans KELSEN, Il problema della sovranità e la teoria del diritto Internazionale. Contributo per una dottrina pura del diritto, a cura di A. Carrino, Milano, Giuffrè, 1989, com uma culta e inteligente introdução de Carrino, p. 6 ss.; veja-se ainda, do mesmo Carrino, L'ordine delle norme. Politica e diritto in Hans Kelsen, Napoli, E.S.I., $1990^{2}$, cap. terceiro, bem como a introdução a: Kelsen e il problema della sovranità, Napoli, E.S.I., 1990).

11 “Poder absoluto e perpétuo de uma República” (tradução nossa). 
independência, de sua própria capacidade e legitimação de dominar a sociedade viva sob a sua própria esfera territorial.

A proposição do moderno como uma comunidade de Estados e do Estado enquanto protagonista histórico senão do moderno implica duas consequências relevantíssimas, as quais, recentemente mencionadas, o jurista tem por obrigação destacá-las.

A primeira consequência é que o Estado cria o direito ou confere a legitimidade a outros entes para que o criem. Detém, por conseguinte, o monopólio ou tende a detê-lo. "Antes do direito há o Estado"; estes são pressupostos históricos e lógicos de toda e qualquer manifestação jurídica, porque cabe-lhe, ao Estado tão somente, qualificar ou não uma regra enquanto jurídica. $O$ direito é uma cria completamente gerada no ventre do Estado, o qual, por sua vez, não admite o convívio simultâneo com outros entes no território sobre o qual incide a sua soberania. Em outras palavras, enclausura-se em uma espécie de casulo hermético, inatacável, indivisível. Para além deste casulo, em seu exterior, restam, portanto, apenas situações de irrelevância e de ilicitude. Não são toleráveis outros ordenamentos jurídicos primários: uma sociedade cavalheiresca, uma comunidade esportiva, uma comunidade religiosa que pretendam criar o direito naquele âmbito específico no qual atuam, em conformidade com os seus interesses são - diante do Estado - situadas no mesmo plano de uma sociedade criminosa, e o resultado é idêntico: irrelevância. Restamos, por assim dizer, sem remédio no campo daquilo que se apresenta como não-direito ${ }^{12}$.

A segunda consequência é o vínculo restrito, como que de subsistência, entre direito e poder político. $O$ direito, todo o direito, é expressão e é voz do poder; sob essa perspectiva, o direito particulariza-se, porque resta inerentemente estigmatizado com as forças particulares e específicas das quais o poder é o portador: o direito dos Códigos do século 19 pode, tranquilamente, ser qualificado como direito burguês, mesmo por aqueles que se dizem distantes da fé marxista, pois decorre da circunstância elementar de ser um produto de uma classe que conquistou, efetivamente, o poder - e mesmo por ser o produto de um Estado que lhe serve, à classe respectiva, de suporte político - e que the imprime, edifica-o, à sua imagem, no respaldo dos seus interesses respectivos e enquanto garantia de controle, realizado por si, da vida social e econômica. Ainda nessa perspectiva, o direito dos códigos modernos não se apresenta como um direito autenticamente privado, mas como direito público avocado para regulamentar as relações privadas,

12 Obviamente, no caso da sociedade criminosa há, para além da irrelevância, a sanção inerente à ilicitude. 
realidade de todo distinta daquela do direito dos privados ${ }^{13}$, na qual a sociedade civil, espontaneamente, a partir de baixo, a partir dos corolários mesmos da experiência quotidiana, identifica e cunha as relações e os institutos jurídicos respectivos, e na qual, ainda são os próprios privados a fonte primária gestadora.

Em outras palavras, o direito é uma projeção do Estado, uma das suas dimensões, e se considera, enquanto uma conquista da civilização jurídica, o rigoroso princípio da territorialidade: um único Estado para um também único território, um único direito para o respectivo território (excetuem-se - evidentemente - as regras excepcionais previstas pelo direito internacional privado).

Diante da hipótese de lacunas na legislação positiva, se todo Código do século 19 faz menção ao direito natural (como, em tantas passagens suas, o obscuro Allgemeines Bürgerliches Gesetzbuch austríaco de 1811) ou aos princípios gerais do direito (como o nosso Código unitário de 1865) ${ }^{14}$, o vigente Código Civil italiano reitera que o último recurso consiste sempre no amparo aos "princípios gerais do ordenamento jurídico do Estado" (ITÁLIA, 1942, art. 12 das Disposições sobre a lei em geral); encerramento perfeito de um círculo que não se distancia do âmbito do direito positivo oficial ${ }^{15}$.

E seria de todo impertinente se alguém apontasse tratar-se essa norma de uma afetação notória do então regime autoritário presente na Itália quando da redação do Código. Aquela norma está, a bem da verdade, ali no Código intacta há mais de

13 Resta implícita a remissão a um célebre ensaio de teoria do direito: SFORZA, 1963.

14 No artigo 3, cuja dicção genérica permite as interpretações mais diversas e mesmo disputas intensas. Como é sabido, uma das quais - talvez a mais ampla e vivaz - é aquela à qual se referiu o filósofo do direito italiano Giorgio Del Vecchio, quando da sua prolusão romana de 1920, interpretando a dicção como referência aos princípios da "razão jurídica natural” (1921), também em Studi sul diritto, vol. I, 1958, p. 254 ss.). 0 problema da identificação dos princípios gerais do direito recebeu, ainda recentemente, bastante atenção por parte dos juristas, teóricos gerais e filósofos do direito; constituiu, por exemplo, o tema do XV Encontro Nacional da Sociedade Italiana de filosofia jurídica e política, em 1985. A última reflexão coletiva (com resultados, registre-se, decepcionantes), é também aquela promovida pela Accademia dei Lincei, em 1991, e cujos anais constituem o volume 96 dos "Atti dei Convegni Lincei": I principi generali del diritto (Roma, 27-29 de maio de 1991), Roma, Accad. Naz. Dei Lincei, 1992.

15 Tal advertência foi pontualmente realizada pelos juristas italianos reunidos em Pisa, em maio de 1940, para discutirem a intenção manifestada pelo então Ministro da Justiça, Dino Grandi, de obter a aprovação pelo Gran Consiglio dos princípios gerais do ordenamento jurídico fascista. Preciso é o juízo que representa o artigo 12, em relação ao anterior artigo 3o do Código de 1865, "um enrijecimento" (conforme falara em sua relação decididamente crítica, um convicto gentiliano como Giuseppe Maggiore, Sui principî generali del diritto, In: Studi sui principî generali dell'ordinamento giuridico fascista, 1943, p. 83) que representa a superação e o sepultamento das disputas então recentes, de vinte anos antes, após a prolusão romana de Del Vecchio (cfr. SFORZA, 1943, p. 97; MORTATI, 1943, p. 115; CRISAFULLI, 1943, p. 179; GROSSO, 1943, p. 347). Superação e sepultamento constatados quase com um relevo de generalidade, excetuada a atitude crítica de Maggiore no seu complexo e significativo escrito. 
cinquenta anos da promulgação deste último, após cinquenta anos de existência de uma democracia parlamentar na Itália. E me viria ainda a vontade de dizer: intacta e inquestionada ${ }^{16}$, ao menos pela maioria silenciosa que cultua o direito positivo. De fato - eis o mais grave - aquela norma em nada perturba o civilista comum italiano, o mesmo que tantas vezes rasgou as próprias vestes diante de outras prescrições de conteúdo fascista previstas no Código, revelando, pois, a desarmonia com o sistema dos valores constitucionais e pretendendo-lhas, então, a supressão ou a modificação ${ }^{17}$. Essa norma é perfeitamente útil ao seu inerente positivismo jurídico, cujas reflexões hermenêuticas do maduro século 20 mantiveram substancialmente indiferente ${ }^{18}$;

16 Significativa a preocupação manifestada durante o itinerário de formação do artigo 12 por aqueles que sustentaram, sob o Código de 1865, uma interpretação jusnaturalística da dicção do artigo 3ํ. É o caso de Giorgio Del Vecchio, o filósofo do direito mencionado na nota 14, o qual, tomando nota em 1936 da restrita formulação proposta no Projeto definitivo do novo Código Civil segundo o qual não se falava mais de princípios gerais do direito, mas sim de princípios gerais do direito vigente, redige uma severa nota crítica e a publica não na Rivista especializada, mas no mais difuso jornal cotidiano romano (DEL VECCHIO, 1936; 2002, p. 271). Evasivos, por sua vez, os mais relevantes textos jurídicos italianos no que tange à interpretação publicados nos últimos cinquenta anos. Enquanto Betti limita-se com indiferença a notar que, no artigo 12, trata-se de "fórmula [...] infeliz que piora a primeira, mas da qual não difere substancialmente" (1971, p. 308), Gorla, no seu injustificadamente famoso e por todas as partes citado ensaio sobre os precedentes históricos do artigo 12, limita-se a precisar que a nova dicção tem por objetivo "ser mais clara" (1973, p. 1897); Quadri observa que a carga ideológica se perdeu sem que, para tanto, trouxesse qualquer consequência (1974); Tarello não vai além de salientar de modo inócuo que o artigo 12 contém "uma importante modificação lexical" (1980, p. 294); o mesmo Giuliani - o qual oferece um quadro multifacetado dos vários comportamentos jurisprudenciais em relação aos princípios da Constituição - detém-se na constatação que "o legislador do código civil vigente entendeu por acentuar o caráter normativo" (1983, p. 71). Sintomático ainda que, na manifestação sobre os princípios de direito escrita em 1966 para o Novíssimo Digesto Italiano, Bobbio não saiba fazer melhor do que salientar, de todo desguarnecido, "a incomum e pouco límpida expressão do art. 12" (citando, além disso, de forma incompleta e manipuladora, um fragmento da exposição de motivos do Ministro da Justiça ao Rei), (veja, ora, a posição republicada em BOBBIO, 1994, p. 257), enquanto Guastini, em sua reflexão recentíssima acerca do mesmíssimo tema, no Digesto Quarto, toma nota que "a fórmula do art. 12, 2 parágrafo, disp. prel. c.c refere-se aos princípios de direito positivo e tão somente a esses", e conclui tranquilamente que "o juiz [...] não está autorizado a preencher as lacunas fazendo recurso [...] aos princípios de justiça não positivados na legislação vigente" (1995, p. 347; 1993, p. 458).

170 desconforto emerge, no entanto, a partir dos constitucionalistas, cuja atenção é obviamente direcionada para as novidades da carta constitucional (veja-se um quadro de resumo em PALADIN, 1994) e a partir dos comparatistas, culturalmente mais libertos (cfr. MONATERI, 1987, p. I, e, recentemente, GRANDE, 1996). Imperativo, porém, mencionar também as minoritárias reflexões civilistas marcadas pela sensibilidade ao problema (e não de ontem; cfr. BRECCIA, 1984; PERLINGIERI, 1985; BARCELLONA, 1991; ainda é de se registrar a inusitada abordagem que é possível encontrar nas lições de BIGLIAZZI GERI, 1994); mesmo que não pareça modificada a constante (um exemplo último parece-me o ensaio para além disso, bem informado, acerca de todo o debate hermenêutico - de DENOZZA, 1995).

18 Malgrado a prodigalidade nas citações de Esser, o civilista italiano é surdo aos resultados da análise hermenêutica (cfr. ZACARRIA, 1996, sobretudo o cap. IV da segunda parte: A liberdade do intérprete: criação e vínculo na práxis jurídica); afirmação genérica que, felizmente, sofre de significativas exceções (é imperioso recordar ao menos o nome de Luigi Mengoni). 
utilíssima ao seu estatalismo de jurista devidamente inserido no moderno ${ }^{19}$, que nutre em si mesmo a inatacável convicção de que o Estado e o ordenamento jurídico não podem senão coincidir, são, por assim dizer, uma benéfica e salutar coisa única ${ }^{20}$.

\section{Sociedade, direito, poder político: tipicidade do universo jurídico medieval}

Uma diferente, e diria até mesmo oposta, paisagem jurídica é aquela fornecida pela experiência medieval.

Aqui, o poder político é caracterizado por uma intrínseca incompletude, é e permanece durante toda a idade média um poder incompleto, utilizando-se desta qualificação como um poder não totalizante, não globalizante. Não importa, portanto, que por vezes este poder logre a desempenhar uma máxima efetividade e um alto grau de coação, configurando-se mesmo em tirania, porque se trata sempre de carência ou de ambiguidade de projeto político. Trata-se, portanto, de um poder que não possui dentre as suas finalidades um programa totalizante de absorção da totalidade social ${ }^{21}$.

Demonstra-o a sua congênita indiferença pelo jurídico: o príncipe medieval restringe, de fato, os seus interesses tão somente àquelas atividades correlacionadas diretamente com o exercício do governo, ou àquilo que se poderia denominar hoje

19 Mesmo em personagens de notável robustez cultural, o pervicaz estatismo, enraizado no consciente e no inconsciente, pode constituir o desbotar de qualquer vigilância crítica. Um dos exemplos mais repugnantes é o ofertado por um grande homem, Francesco Ferrara (sênior), em sua grosseira prolusão napolitana, na qual, contemplando o devir do direito ao longo do século, não hesita em escrever: "esta evolução se faz tanto mais quanto sempre mais íntima a cooperação e compenetração entre ordenamento jurídico e poder dos governantes"; e ainda, "o direito, assim, é estreitamente conexo com a política, logo, sofre as finalidades e tendências do Estado" (1940; 1954, p. 124). 0 dado mais alarmante nessas frases não é tanto o tratamento contingente servil ao regime imperante, mas a evidente coincidência entre totalitarismo fascista e convicções estatalistas, coincidência que não permite ao culto civilista perceber a gravidade das consequências de um casamento tão estreito entre direito e Estado, entre direito e aquele Estado. Essas posições estatalistas dos juristas italianos não pertencem tão somente ao remoto passado no qual se situa Ferrara. É tão somente neste sentido que deve ser interpretada a resistência e a hostilidade da maioria em relação àquela noção de direito vivente, que aflora sempre na jurisprudência da nossa Corte Costituzionale com o significado de contraposição a um direito vigente do direito tal qual resulta da efetividade das relações sociais (para se medir as reações da nossa scientia iuris em relação à noção de direito vivente, instrutiva a leitura de PUGIOTTO, 1994, sobretudo a Introdução; é destes dias a repropositura de um ensaio de Mengoni acerca do assunto, o qual tomo a liberdade de recomendar ao leitor: MENGONI, 1996).

20 Surge espontaneamente em nossa mente uma combinação: da parte dos juristas italianos que cultuam o direito positivo, tem-se mencionado frequentemente os ensaios de Esser da mesma maneira em que se tem, frequentemente, mencionado a difamação de Santi Romano acerca da pluralidade dos ordenamentos jurídicos. Bom sinal? Seria-o, certamente, não fosse o fato de vermos cair em um absoluto vazio tais citações que flutuam quase sempre desprovidas de raízes, nas páginas da maioria dos juristas.

21 Para uma maior profundidade e uma leitura mais apropriada acerca deste tema, veja-se a nossa supracitada síntese L'ordine giuridico medievale, 1995. 
de direito constitucional, administrativo, e mesmo o penal, relegando às demais forças a honra de produzir as regras organizacionais da vida quotidiana, as quais brotam, definem-se e sistematizam-se por meio de uma complexa cooperação existente entre fatos espontâneos consuetudinários, interpretatio dos doctores e dos judices. Demonstra-o, outrossim, a singular circunstância na qual o príncipe medieval identifica tanto mais a sua função com a distribuição de justiça do que propriamente com aquela de legislar. Este príncipe é mais o grande justiceiro do seu povo do que um legislador.

O Estado é um porvir, porque nenhum poder político chega a se revestir com a estatalidade. Mesmo no reino da França, que é certamente o laboratório político-jurídico secular no qual toma corpo e se delineia lentamente, e de um modo cada vez mais intenso, um sujeito autenticamente estatal, o processo tem uma fase embrionária ainda no século 13 com uma vigilante atenção da Monarquia no que tange ao fenômeno consuetudinário, mas que verifica um seu início mais robusto tão somente no século 14 , o qual se apresenta como momento de crise para a ideologia política medieval.

Inexiste o grande titereiro e irrisória é a manifestação legislativa do direito. 0 poder não tem a presunção de criá-lo, mas, pelo contrário, deixa aos juristas e aos operadores práticos (juízes e notários) o pesado ofício de extraí-lo e de defini-lo a partir de uma profunda plataforma consuetudinária.

Ei-lo, o ponto caracterizante: o direito pertence, na realidade medieval, às profundezas da sociedade. Trata-se de radícula, é uma ordem cuja vida está em um nível distinto daquele confuso e conflituoso da superfície sóciopolítica, e que guarda, obviamente, pouquíssima relação com essa superfície. O direito, exatamente na medida desta sua dimensão radicular, não se confunde, pois, com os entes políticos que transitam e transmudam convulsamente. Diante da instabilidade e da fluidez do político, o direito representa a estabilidade e a robustez do social. E, aos nossos olhos, mostra-se difusa a consciência de que ali se encontra a salvação, o ancoradouro seguro de uma sociedade superficialmente desconfigurada e desordenada.

Em sentido contrário àquele que apontamos enquanto caracterizador do mundo moderno, o direito é pressuposto lógico e histórico em relação aos sujeitos políticos. Antes havia o direito: primado ontológico e primado histórico. Justamente em decorrência deste primado é que o direito se origina (e continua, pois, a subsistir) com uma sua autonomia prevalente por sobre o político, restando, portanto, de todo a salvo do abraço sufocante do poder. Por óbvio que, pela carnalidade do direito, ou seja, por servir e ser medido em relação aos homens de carne e osso, não restará, 
seguramente, escrito nas nuvens e nem, tampouco, flutuará, rarefeito, por sobre a paisagem histórica, mas, ao contrário, será sempre uma enorme pluralidade de forças - econômicas, sociais, culturais, espirituais - que o sustentará, fundamenta-lo-á e que the configurará, por assim dizer. É exatamente por tal motivo que se apresenta enquanto oposto ao direito moderno: não se trata de mera voz potestativa, nem tampouco por meio dela se particulariza ou sequer com ela se identifica.

Por tal motivo, caberá a uma ampla pluralidade de fontes produzir o direito, quase que como a comprovar efetivamente que o nexo existente é entre direito e sociedade, que o direito exprime a sociedade em sua completude e para a qual nasce, para ordená-la. Por isso, as referidas fontes não possuem uma conexão com uma correlação hierárquica e, mesmo nesta última, a lei possui um papel absolutamente secundário enquanto manifestação volitiva do titular do poder. Trata-se, portanto, de uma invenção completamente moderna a caracterização de superioridade da lei e a sua consequente projeção enquanto protagonista, e, logo, dominante ${ }^{22}$.

\section{A noção de autonomia enquanto adequado modelo ordenador para a compreensão da constituição jurídica medieval}

Ultrapassadas essas considerações iniciais, analisar o direito medieval com os óculos indiscriminadamente modernos não é senão de todo ludibriador.

Se tudo o que falamos é verdade, ou seja, que o direito medieval não é mera sombra deste ou daquele ente político, mas é realidade radicular unida em estreitíssimos vínculos com a constituição mais nevrálgica, mais íntima da inteira completude social, e representa, portanto, a ordem ali sedimentada, prosseguir numa análise da dimensão jurídica medieval, tal qual nos é apresentada no mundo moderno, em conexão exclusiva com o Estado e com a sua soberania, implica querer medir os corpos medievais, com as suas dimensões particulares, utilizando-se de uma régua moderna. A medida restará desfalcada; o resultado, aberrante.

O hábito mental do jurista moderno, profundamente convencido por dois séculos de uma exitosa propaganda iluminista, tende naturalmente a individualizar tão somente um único direito para um correspondente e também único Estado; visão monista para a qual, à solidão do único produtor, faz-se necessário o contraponto da solidão de um único ordenamento jurídico. 0 que, porém, mostra-se perfeitamente

22 Fundada essencialmente naquela presunção apodítica de identidade entre lei e vontade geral, cuja afirmação e enunciação encontra sua manifestação mais clara, e robusta, da Revolução até mesmo aos seus iniciais incunábulos (cfr. artigo 6 da Déclaration de 1789). 
coerente enquanto corolário, mesmo se, não sem drama, completamente reducionista da fartura e da riqueza da experiência jurídica.

A não correlação medieval entre o direito e o poder político e, ainda, a vinculação do direito a toda a complexidade do social acarretam, por vias outras, um inafastável pluralismo jurídico; um abundante pluralismo para o qual uma consciência estatalista e a utilização, então, de modelos também estatalistas levam, senão para além da não compreensão, a uma deformação tosca. $O$ banho de purificação ao qual deve se submeter o historiador do direito é justamente o abandono sem quaisquer arrependimentos, e distante de quaisquer resíduos, do hábito mental ora mencionado. Deve, o historiador do direito, pelo contrário, assumir como hipótese fundamental uma sociedade na qual são manifestos, em um mesmo território submetido a uma mesma entidade política, os mais diversos ordenamentos jurídicos.

Estamos conscientes de que não dizemos, ora, nada de novo. Todo historiador do direito tem a consciência de que essa operação interpretativa foi já completada, há tempos, por Francesco Calasso ${ }^{23}$, o qual não titubeou ao transplantar para o terreno da experiência medieval o sugestivo traçado, esquissado pelo juspublicista italiano Santi Romano, ainda em 1918, acerca da pluralidade de ordenamentos jurídicos ${ }^{24}$. Calasso, nos moldes de S. Romano, poderia certamente intitular a sua obra mais importante Gli ordinamenti giuridici del rinascimento medievale (1949), fazendo, então, a partir da teorização romaniana o modelo interpretativo de toda a juridicidade medieval.

Foi certamente um sinal de acuidade e de sensibilidade cultural; foi ainda um assaz e merecido fortalecimento para a análise histórico-jurídica. Mas, além disso, foi também um experimento imperfeito, inacabado, porque, ainda que Calasso fosse o propositor de uma intuição fértil, não fora capaz de levá-la à sua ulterior, e natural, consequência. E quando digo não foi capaz, refiro-me, registro, a um complexo de condicionantes inerentes à mentalidade de moderno da qual Calasso não soube, e nem o poderia, libertar-se.

O banho de purificação, para reafirmar uma expressão anterior, se apresentou, a Calasso, superficial e, portanto, não despertou a completa revisão dos hábitos mentais que seria libertadora. Libertadora, antes de tudo, em relação ao material

23 Exclusivamente para o leitor não italiano, ora registramos alguns mínimos dados biográficos: nascido em 1904, na comuna de Lecce; por longo período ensinou História do direito italiano nas Universidades de Florença e de Roma; faleceu, prematuramente, em 1965. A ele se deve uma verdadeira e autêntica renovação da metodologia e no próprio programa dos estudos histórico-jurídicos na Itália.

24 ROMANO, S., 1946. Vide a tradução para o português da referida obra: ROMANO, S., 2008. 
histórico-jurídico medieval não completa e devidamente historicizado, decorrência de uma restritiva visão moderna. Calasso continua, de fato, a mencionar o Estado e a soberania dentro de uma perspectiva teórica que se apoia por sobre a ideia central de uma pluralidade de ordenamentos jurídicos. O que se apresenta, inafastavelmente, antinômico.

Calasso não compreendeu que admitir uma pluralidade de ordenamentos jurídicos implica inevitavelmente admitir uma realidade jurídica - qualquer que seja - inserida, de forma indissociável, em um complexo tecido de relações, tecido que infalivelmente condiciona e relativiza a posição de qualquer realidade; porque se trata - necessariamente - de realidades que convivem em um mesmo território e, convivendo, limitam-se de forma recíproca ou que podem conviver harmonicamente, visto que nenhuma delas refere-se a uma dimensão particular da juridicidade: a comunidade internacional, a comunidade religiosa, a comunidade política, a comunidade profissional e assim por diante.

É este o quadro da complexa realidade jurídica medieval: sobre uma plataforma de uma sociedade que fervilha de tantas outras sociedades vitais, um quadro de interrelações e de limitações recíprocas. Se assim o é, uma noção apresenta-se inutilizável diante dos nossos olhos: a noção de soberania. A razão é claríssima: a soberania é, como já mencionamos alhures, uma noção totalizante, absolutista, isolante. Soberania é um absoluto que até pode, convenientemente, servir àquele também absoluto que é o Estado, mas que não convém, certamente, a um ordenamento jurídico constatado em meio a tantos outros, ou seja, no centro de um profundo tecido ordenamental. A soberania é uma noção que tem em si um determinante conteúdo exclusivo, o qual não convém a uma mentalidade jurídica como aquela medieval, em que é substancialmente descabido pensar em termos de exclusividade.

A primeira barreira a se transpor é uma só: varrer do nosso caminho pedras como - Estado e a soberania, por serem completamente incapazes de ordenar a realidade jurídica medieval. Isso Calasso não tratou de fazer, acarretando a condenação de sua elevada e inovadora abordagem à aridez de uma irreparável antinomia.

Talvez coubesse uma maior atenção às (mesmo que formalmente por Calasso conhecidas) reflexões do último Romano, as quais sintetizavam e assimilavam as constatações contidas nas páginas do L'ordinamento giuridico (1946). Referimo-nos especificamente aos Frammenti di un dizionario giuridico (1953, p. 14), que remontam a 1946, e nos quais destaca com precisão, o grande Santi Romano, a noção de autonomia, noção eminentemente polissêmica, mas que, compreendida em seu 
sentido de autonomia institucional, nos é apresentada, subjetivamente, como "o poder de produzir para si próprio um ordenamento jurídico", e, objetivamente, "como uma característica inerente a um ordenamento jurídico pela qual os indivíduos ou entes constituem-se por si próprios" (CALASSO, 1959) ${ }^{25}$.

A análise romaniana é de todo valorosa porque se coloca a partir de uma perspectiva livre e arejada de teoria geral do direito e não incorre, desse modo, na pauperização que, por vezes, força o juspublicista a frequentemente falar de autonomia, mas a partir de uma perspectiva sempre interna e indissociável ao/do poder do Estado. Não diríamos que a análise romaniana seja de todo satisfatória, pois mesmo esta apresenta-se jaspeada por algumas aporias e não logra uma completa clareza acerca de diversos significados e perspectivas nas quais a noção pode se situar; mas ela possui, por outro lado, o considerável mérito de identificar na autonomia o mecanismo estrutural e funcional de uma pluralidade de ordenamentos jurídicos. Se enriquecermos e mesmo corrigirmos essa análise com as sucessivas reflexões conduzidas, na doutrina italiana, por um publicista culto e sagaz como o é Massimo Severo Giannini $(1952)^{26}$, encontramos à nossa disposição, então, um instrumento teórico que, compreendido enquanto autonomia institucional (1952, p. 208209), se nos mostra como adequadíssimo para ordenar (e mesmo para consentir com uma adequada compreensão de) a constituição jurídica medieval.

0 resultado que temos é um distanciamento evidente, quase uma oposição lógica, entre autonomia e soberania. Esta última isola o sujeito cuja titularidade lhe cabe - indivíduo ou ente - em uma sua solidão absoluta. É uma posição que prescinde de quaisquer contribuições provenientes de fora do seu casulo, intensificando ao máximo a separação do sujeito soberano de tudo aquilo que não o seja, de todo o resto. A soberania - como noção estandarte da exclusividade - é um concreto que enclausura o sujeito em um invólucro de particular espessura e de inatacabilidade, constituindo-lhe, então, como um universo fechado em si mesmo.

Autonomia, por outro lado, é inerentemente uma posição de relação ${ }^{27}$. Se, por um lado, é suficiente afirmar que um sujeito é soberano, por outro, de fato, não é suficiente

25 Tímido, entretanto, é o verbete Autonomia a) Premissa histórica, esquissada por Calasso (ENCICLOPEDIA DEL DIRITTO, 1959).

26 Veja-se ainda, do mesmo autor, o verbete Autonomia b) Teoria generale e diritto pubblico (1959). 0 primeiro ensaio gianniniano é de todo relevante para um definitivo esclarecimento - no âmbito da global e complexa noção geral de autonomia - entre o perfil da autonomia normativa e aquele da autonomia institucional.

27 Veja-se acerca deste ponto específico as reflexões lúcidas e conscientes que desenvolve ROMANO,A., 1987, um verbete de prevalente conteúdo publicístico, mas com incisivas notas esclarecedoras de teoria geral (sobretudo p. 32-33). 
afirmar que um sujeito é autônomo, mas é necessário acrescentar e especificar de quem e em relação a quem. Autonomia significa sempre uma correlação, relação com alguém: enquanto independência relativa, não pode senão considerar um sujeito em estreita correlação com outros sujeitos, um sujeito que, em decorrência dessa correlação, acaba por limitar a esfera de independência de outros ou, por outros, fazer-se limitar. A relatividade e a elasticidade são as características essenciais da autonomia tanto quanto o absolutismo e a exclusividade o são para a soberania.

É uma chave de leitura jurídica da constituição medieval que se apresenta imediatamente enquanto esclarecedora; e que, para dizer mais, permite compor harmonicamente um nó de relações que, observado com lentes desajustadas, se nos apresenta irremediavelmente como um nó górdio. A constituição medieval não é articulada em um arquipélago de soberanias, mas em um tecido de autonomias. Há tão somente uma soberania, e enorme em sua absolutez, mas cai por sobre ela, vinda de cima, a chuva: ei-lo, o Senhor. Abaixo, o mundo jurídico medieval é e permanece sendo um mundo de autonomias.

É esta a única maneira para ordenar as situações complexas, praticamente indecifráveis: a convivência - em um mesmo território - de direito comum e de direitos particulares. $\mathrm{O}$ emaranhar-se contínuo entre direito imperial, direito canônico, direito estatutário, direito feudal, direito mercantil, que tão somente o relativismo e a elasticidade da noção de autonomia permite compreender, ou seja, enquanto existência e vigência comum de inúmeros ordenamentos, de várias autonomias que elasticamente se comprimem em uma dialética perene entre universal e particular, entre geral e especial, e que não permite mais rupturas e fracionamentos. Este tecido sóciojurídico medieval, que, à primeira vista, faz parecer um emaranhado inextricável, pode receber uma luz definitiva a partir de uma perspectiva pluriordenamental enquanto interação de sujeitos autônomos não soberanos.

Emerge firme a conclusão já apontada no título deste nosso ensaio: um direito sem $\mathrm{Estado}^{28}$, um direito que se une imediatamente ao social e, então, exprime-o em sua completude. E há - talvez como jamais houve - uma compenetração entre o jurídico e o social. 0 direito é a recôndita ossatura da sociedade, a sua fundação, a sua estabilidade. Repetimo-lo novamente: é a sua salvação.

28 Há alguns anos foi, aproximadamente, este o título de um livro de Laurent Cohen-Tanugi, que tivera alguma circulação e a honra de bastante citações: Le droit sans l'Etat. Sur la démocratie en France et en Amérique, 1985. Como bem demonstra o subtítulo, o tema de Cohen-Tanugi se movia tocquevillianamente em uma comparação entre duas estruturas político-jurídicas, a francesa e a estadunidense. 0 horizonte não guarda qualquer correlação com o nosso. 
Que me seja consentido concluir estas reflexões destacando ao leitor um paralelismo esclarecedor entre aquilo que ocorre em um "território" e aquilo que ocorre em um "patrimônio". O mundo moderno tem soluções absolutistas e exclusivistas: apenas um Estado e um só ordenamento jurídico para um só território; tão somente um sujeito proprietário e uma só propriedade unitária para um só patrimônio ${ }^{29}$. 0 mundo medieval, ainda que sob uma perspectiva patrimonial, faz escolhas exatamente opostas: como o direito em um determinado território é intuído e resolvido enquanto pluralidade de ordenamentos que convivem, logo, com um paralelismo exemplar e coerente, sobre um mesmo bem são cogitáveis várias propriedades. Cada uma delas, as propriedades, não possuem ainda o ulterior caráter absoluto erigido pela propriedade burguesa, mas um específico conteúdo de autonomia, conteúdo relativo e relativizante, como lhe é, à noção, inerente. Quando Bartolo identifica no perfecte disponere a característica de toda propriedade, refere-se, com toda a evidência, a uma autonomia dos poderes sobre o bem, a única posição que permite compreender diversas propriedades harmonicamente incidentes sobre um mesmo bem ${ }^{30}$. $\mathrm{O}$ perfecte disponere de Bartolo avoca imediatamente o farto entrelaçamento medieval enquanto societates iuridice perfectae. E é sempre a mesma noção - isto é, autonomia, perfectio - a sustentar toda a vida e a construção do social e do jurídico.

É ainda e sempre a mesma incapacidade e - diria ainda mais - repugnância a absolutizar. A inclinação do moderno a isolar, individualizar, absolutizar - seja essa a realidade única que é o Estado, ruptura e divisão irreparável da universal tunica inconsutilis ${ }^{31}$; seja essa a realidade única que é o indivíduo - abandona uma visão genuinamente pluralista, na qual o que parece mais importar é a relação, o vínculo que une e limita realidades diversas.

Prosseguindo no paralelismo ora definido, é tão somente no moderno que se verificam as posições isoladoras e absolutizadoras da soberania e do direito subjetivo, em uma verdadeira oposição entre sujeito político e sujeito privado, dois sujeitos então solitários, libertos da humilhação daquele tecido de correlações que a mentalidade medieval, ao redor deles, jamais hesitou em tecer.

290 que não é de forma alguma desmentido, mas mesmo corroborado, pela construção rigorosamente individualista que, na mesma esteira daquela de tradição romanística, faz-se em relação ao condomínio na cultura jurídica moderna.

30 Para a interpretação da definição batoliana de dominium, cfr. GROSSI, 1968.

31 Referida expressão - como o sabe qualquer medievalista - representa o ápice da extrema manifestação da teocracia papal contida na bula Unam sanctam, de 1302, do pontífice Bonifácio VIII, (inserida - e comodamente legível - no Corpus iuris canonici, ed. Aem. Friedberg, rist. Anast. Graz, Akad. Druck, 1959, pars secunda, Extravagantes communes, I, VIII, I). Resta evidente a derivação escrita. 


\section{Referências}

AUSTRIA. Allgemeines Bürgerliches Gesetzbuch. JGS, n. 946/1811.1811. Disponível em: $\quad$ http://alex.onb.ac.at/cgi-content/alex?aid=jgs\&datum $=10120003 \&$ sei te $=00000275$. Acesso em: 8 abr. 2019.

BARCELLONA, M. L'interpretazione del diritto come autoriproduzione del sistema giuridico. Rivista critica del diritto privato, IX, 1991.

BETTI, E. Interpretazione della legge e degli atti giuridici (Teoria generale e dogmatica). Milano: Giuffrè, 1949.

. Interpretazione della legge e degli atti giuridici (Teoria generale e dogmatica). 2. ed. Milano: Giuffrè, 1971.

. Diritto romano e dogmatica odierna. Archivio giuridico Filippo Serafini, v. 99, fasc. 2. 1. ed. Modena: Societa tipografica modenese, 1928.

. Diritto metodo ermeneutica: scritti scelti. A cura di Giuliano Crifò. Milano: Giuffrè, 1991.

BOBBIO, N. Contributi ad un dizionario giuridico. 1. ed. Torino: Giappichelli, 1994.

BODIN, J. Les six livres de la République. 2. ed. Aalen: Scientia Verlag, 1977.

BRECCIA, U. Problema costituzionale e sistema privatistico. Rivista critica del diritto privato, II, 1984.

COHEN-TANUGI, L. Le droit sans l'Etat. Sur la démocratie en France et en Amérique. Paris : Presses universitaires de France (P.U.F), 1985.

CRISAFULLI, V. Per la determinazione del concetto dei principî generali del diritto. In: Studi sui principi generali dell'ordinamento giuridico fascista. A cura della Facoltà di giurisprudenza e della Scuola di perfezionamento nelle discipline corporative della R. Università di Pisa. Regia Università Degli Studi Pisa, Facoltà Di Giurisprudenza. Pisa: Pacini Mariotti, 1943.

DEL VECCHIO, G. Sui Principî generali del diritto. Milano: Giuffrè, 1921.

. Studi, sul diritto. Milano: Giuffrè, 1958.

DENOZZA, F. La struttura dell'interpretazione. Rivista trimestrale di diritto e procedura civile, XLIX, 1995. 
ENCICLOPEDIA DEL DIRITTO. Verbete “Autonomia”. Enciclopedia del diritto. 4. ed. Milano: Giuffrè, 1959.

FERRARA, F. Rinnovamento del diritto civile secondo i postulati fascisti. [S.l.]: [S.n.], 1940.

. Rinnovamento del diritto civile secondo i postulati fascisti. In: Scritti giuridici. Vol. I. Milano: Giuffrè, 1954.

GERI, L. L’interpretazione - Appunti delle lezioni di teoria generale del diritto. Milano: Giuffrè, 1994.

GIANNINI, M. Autonomia (saggio sui concetti di autonomia). Rivista Trimestrale di Diritto Pubblico, Roma, v. 2, 1951, p. 851-883.

. Teoria generale e diritto pubblico. In: Enciclopedia del diritto IV. Milano: Giuffrè, 1959.

GIARDINA, A.; ROLANDO, Q. Dell'applicazione della legge in generale, art. 10-15. In: Commentario del Codice civile. 1 ed. Bologna: [s.n.], 1974.

GIULIANI, A. L’applicazione della legge. Rimini: Maggioli, 1983.

GORLA, G. I precedenti storici dell'art. 12. Disposizione preliminar del Codice civile del 1942 (un problema di diritto costituzionale). In: Studi in memoria di Carlo Esposito. Padova: Cedam, 1973.

GRANDE, E. Principio di legalità e diritto giurisprudenziale: un'antinomia? Politica del diritto, XXXVII, n. 3, setembro de 1996.

GROSSI, P. Le situazioni reali nell'esperienza giuridica medievale. Padova: Cedam, 1968. . L'ordine giuridico medievale. 11. ed. Bari: Laterza 1995.

GROSSO, G. Principî generali dell'ordinamento giuridico o dichiarazione politica? In: Studi sui principi generali dell'ordinamento giuridico fascista. A cura della Facoltà di giurisprudenza e della Scuola di perfezionamento nelle discipline corporative della R. Università di Pisa. Regia Università Degli Studi Pisa, Facoltà Di Giurisprudenza. Pisa: Pacini Mariotti, 1943.

GUASTINI, R. Principî di diritto in Digesto IV. Torino: Utet, 1995. . Le fonti del diritto e l'interpretazione. 1. Ed. Milano: Giuffrè, 1993. 
HAURIOU, M. Die Theorie der Institution und zwei andere Aufsätze. Mit einer Einleitung und Bibliographie. 1. ed. Berlin: Duncker \& Humblot, 1965.

HELLER, Herman. La sovranità-Contributo alla teoria del diritto dello Stato e del diritto Internazionale. Milano: Giuffrè 1987.

. La sovranità ed altri scritti sulla dottrina del diritto e dello Stato. Milano: Giuffrè, 1987.

ITÁLIA. Código Civil Italiano. Edição extraordinária da Gazeta Oficial n. 79, de 4 abr. 1942. Disponível em: https://www.gazzettaufficiale.it/sommario/codici/codiceCivile ;jsessionid=uwk+xc4zz1dN+799th595g_.ntc-as3-guri2b. Acesso em: 8 abr. 2019.

KELSEN, H. Il problema della sovranità e la teoria del diritto Internazionale. Contributo per una dottrina pura del diritto. 1. ed. Milano: Giuffrè 1989. 1990.

. L'ordine delle norme. Politica e diritto. Napoli: Edizioni Scientifiche Italiane,

MAGGIORE, G. Sui principî generali del diritto. In: Studi sui principî generali dell'ordinamento giuridico fascista. A cura della Facoltà di giurisprudenza e della Scuola di perfezionamento nelle discipline corporative della R. Università di Pisa. Regia Università Degli Studi Pisa, Facoltà Di Giurisprudenza. Pisa: Pacini Mariotti, 1943.

MIGLIO, G. Genesi e trasformazioni del termine-concetto 'Stato’. [S.L.]: [S.n.], 1981.

. Le regolarità della politica. Milano: Giuffrè, 1988.

MITTEIS, H. Der Staat des hohen Mittelalters. Weimar: Böhlau, 1940.

MONATERI, P. G. Interpretare la legge (I problemi dei civilisti e le analisi del diritto comparato). Rivista di diritto civile, XXXII, p. I, 1987.

MORTATI, C. Osservazioni sulla natura e funzione di una codificazione dei principi generali di diritto. In: Studi sui principi generali dell'ordinamento giuridico fascista. A cura della Facoltà di giurisprudenza e della Scuola di perfezionamento nelle discipline corporative della R. Università di Pisa. Regia Università Degli Studi Pisa, Facoltà Di Giurisprudenza. Pisa: Pacini Mariotti, 1943.

PALADIN, L. Costituzione, preleggi e Codice civile, in Il Codice civile. In: CONGRESSO DO CONQUENTENÁRIO DEDICADO À FRANCESCO SANTORO PASSARELLI, Roma, 1516 de dezembro de 1992. Roma: Accad. Naz. Dei Lincei, 1994. 
PERLINGIERI, P. L'interpretazione della legge come sistematica ed assiologica. II brocardo in claris non fit interpretatio, il ruolo dell'art. 12 disp. prel. c.c. e la nuova scuola dell'esegesi, Rassegna di diritto civile, VI. [S.L.]: Edizioni scientifiche italiane, 1985.

PUGIOTTO, Andrea Sindacato di costituzionalità e “diritto vivente”. Genesi, uso, implicazioni. 2. ed. Milano: Giuffrè, 1994.

QUADRI, R. Dell'applicazione della legge in generale, art. 10-15. In: Commentario del Codice civile, a cura di A. Scialoja e G. Branca. Bologna: Zanichelli, 1974.

ROMA. I principi generali del diritto (Roma, 27-29 de maio de 1991). Roma: Accademia Nazionale dei Lince, 1992.

ROMANO, A. Autonomia nel diritto pubblico. In: Digesto-quarta edizione-Disipline pubblicistiche. Torino: Utet, 1987. vol. II.

ROMANO, S. Die Rechtsordnung. Mit einen Vorwort, biographischen und bibliographischen Notizen hrsg. v. Roman Schnur. 44. ed. Berlin: Duncker u. Humblot, 1975.

. Frammenti di un dizionario giuridico. 1. ed. Milano: Giuffrè, 1983.

Gli ordinamenti giuridici del renascimento medievale. Milano: Giuffrè, 1949.

L'ordinamento giuridico. 2 ed. Firenze: Sansoni, 1946.

2008

O ordenamento jurídico. Tradução de Arno Dal Ri Jr. Florianópolis: Boiteux,

ROSSI, Luigi. Studi di diritto costituzionale in memoria di Luigi Rossi. 1. ed. Milano: Giuffrè, 1952.

SFORZA, W. C. Il diritto dei privati (1929). 2. Ed. Milano: Giuffrè, 1963.

Verso la carte del diritto. In: Studi sui principi generali dell'ordinamento giuridico fascista. A cura della Facoltà di giurisprudenza e della Scuola di perfezionamento nelle discipline corporative della R. Università di Pisa. Regia Università Degli Studi Pisa, Facoltà Di Giurisprudenza. Pisa: Pacini Mariotti, 1943.

TARELLO, G. L’interpretazione della legge. 1 ed Milano, Giuffrè, 1980.

TREVES, R.; CARRINO, A. Kelsen e il problema della sovranità. Napoli: Edizioni Scientifiche Italiane, 1990.

ZACCARIA, G. Questioni di interpretazione. Padova: Cedam, 1996. 